\title{
Percutaneous Transjejunal Retrograde Cholangiogram as Alternative Biliary Access in Patients with Previous Roux-en-Y Surgery
}

\author{
${ }^{1}$ Department of Radiology, Alfred Health, Melbourne, VIC, Australia \\ ${ }^{2}$ Department of Surgery, Monash University Central Clinical School, \\ Melbourne, VIC, Australia \\ ${ }^{3}$ National Trauma Research Institute, Monash University, Melbourne, \\ VIC, Australia \\ ${ }^{4}$ Department of Gastroenterology, Alfred Health, Melbourne, VIC, \\ Australia \\ ${ }^{5}$ Department of Gastroenterology, Monash University Central \\ Clinical School, Melbourne, VIC, Australia
}

Warren Clements ${ }^{1,2,3, \odot}$ Ronny Kuang ${ }^{1, \odot}$ Ammar Majeed ${ }^{4,5, \odot}$ Tim Joseph ${ }^{1, \odot}$

J Gastrointestinal Abdominal Radiol ISGAR 2021;4:166-167.

Interventional radiologists (IR) play an important role in the management of biliary tract obstruction. For patients with previous gastric or upper abdominal surgery, the choledochojejunostomy may be difficult to access with endoscopic retrograde cholangiopancreatography (ERCP).

A 61-year-old lady underwent Roux-en-Y for pancreatic lymphoma 35 years ago. The choledochojejunostomy remained patent until 2014 when she first experienced an episode of cholangitis. - Fig. 1A shows marked intrahepatic ductal dilatation tapering at the anastomosis. As the anastomosis was not accessible for ERCP, percutaneous transhepatic cholangiography (PTC), brushings, and dilatation were performed. Intravenous antibiotic prophylaxis was used. However, this resulted in septic shock necessitating a 5-day admission to the intensive care unit (ICU). Brushings returned negative for malignancy. The stricture recurred and repeat PTC in January 2018 also resulted in ICU admission. In the 12 months prior to referral to IR, the patient had five further admissions for cholangitis, treated with antibiotics.

After multidisciplinary discussion, percutaneous transjejunal retrograde cholangiography (PTJRC) was planned as alternative access given episodes of sepsis post-PTC. The patient lacked central adiposity and the biliary limb was close to the abdominal wall ( $\mathbf{- F i g . ~ 1 B )}$ that was favorable for this approach.

With the patient under light sedation and with intravenous $1 \mathrm{~g}$ ceftriaxone prophylaxis, the jejunum was punctured with a 22G micropuncture access kit (Cook Medical, Bloomington, United States) using ultrasound and fluoroscopic guidance
Address for correspondence Warren Clements, BBiomedSc (Hons), MBBS, FRANZCR, EBIR, Department of Radiology, Alfred Health, 55 Commercial Road, Melbourne, VIC 3004, Australia (e-mail: w.clements@alfred.org.au).

and 6-French sheath was inserted. A catheter (5-French $45 \mathrm{~cm}$ Bern tip, Cook Medical, Bloomington, United States) was used to cannulate the biliary duct in a retrograde manner and a retrograde cholangiogram performed, identifying high-grade anastomotic stenosis with intraductal calculi ( $\mathbf{- F i g}$. 2A). The anastomosis was dilated serially to $6 \mathrm{~mm}$. At the conclusion, the sheath was removed and a 2-0 silk purse-string suture used to close the jejunostomy. The patient remained clinically well after the procedure and was discharged the following day.

In the 6 months after the treatment, there were no episodes of cholangitis. A repeat procedure was performed in a similar manner at 6 months and the anastomosis dilated up to $9 \mathrm{~mm}$ ( $\boldsymbol{- \text { Fig. }}$. 2B) with balloon-assisted extraction of intraductal calculi. The patient has required no further intervention at up to 9 months.

There is limited description of transjejunal access for biliary duct intervention with much of the literature predating the 2000s. ${ }^{1}$ In recent literature, there have been predominantly small case series advocating alternative approaches to PTC in patients with appropriate jejunal anatomy. ${ }^{2-5}$ The transjejunal approach offers the ability to access the entire biliary tree from a single approach, and has the potential for less discomfort and potential risk for hemorrhage than for transhepatic access. This is particularly useful if repeated access may be needed such as intervention on a benign stricture.

In our patient, recurrent septic shock made PTJRC a favorable alternative to PTC. The use of ultrasound to identify the jejunal loop was simple and allowed infiltration of lidocaine published online February 15, 2021
DOI https://doi.org/

$10.1055 / \mathrm{s}-0041-1722812$ ISSN 2581-9933. (c) 2021. Indian Society of Gastrointestinal and Abdominal Radiology. This is an open access article published by Thieme under the terms of the Creative Commons Attribution-NonDerivative-NonCommercial-License, permitting copying and reproduction so long as the original work is given appropriate credit. Contents may not be used for commercial purposes, or adapted, remixed, transformed or built upon. (https://creativecommons.org/licenses/by-nc-nd/4.0/).

Thieme Medical and Scientific Publishers Pvt. Ltd. A-12, 2nd Floor, Sector 2, Noida-201301 UP, India 

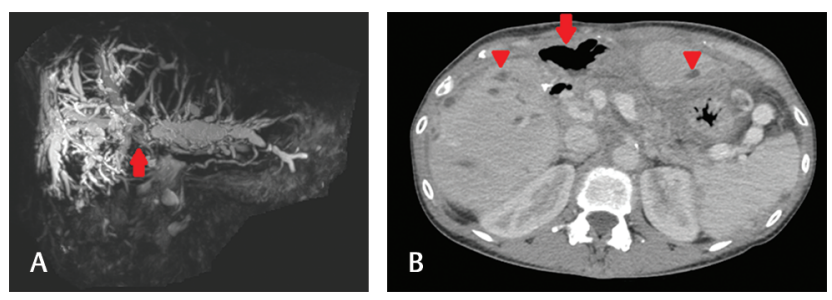

Fig. 1 (A) Magnetic resonance cholangiopancreatography showing intrahepatic ductal dilatation tapering at a central stricture (arrow). (B) Portal venous phase computed tomography showing biliary limb of the Roux-en-Y close to the anterior abdominal wall (arrow) and intrahepatic ductal dilatation (arrowhead).
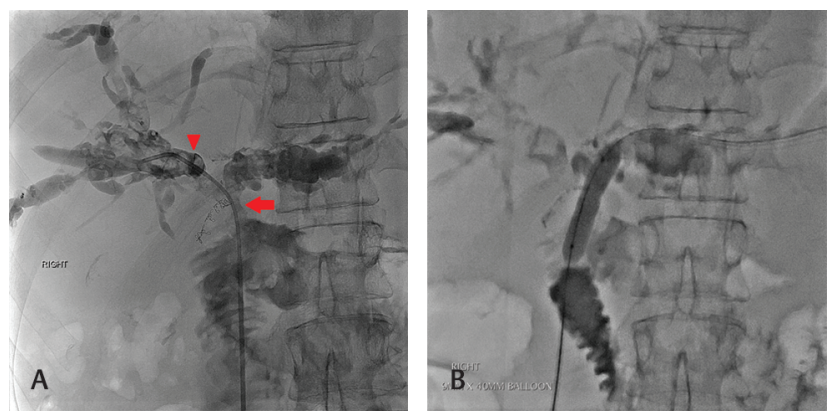

Fig. 2 (A) Retrograde cholangiogram showing anastomotic stenosis (arrow) and intraductal calculi (arrowhead). (B) Retrograde anastomotic dilatation using $9 \times 40 \mathrm{~mm}$ balloon (Rival 0.035, BD Bard, Franklin Lakes, United States).

to the peritoneum. This combined with avoiding the need to traverse the hepatic capsule and parenchyma allowed the procedure to be performed under light sedation. On the initial access, the loop was gas-filled and a combination of ultrasound and fluoroscopic guidance was used. Gastropexy fasteners were not required.
The authors hope to encourage the use of PTJRC when feasible as an alternative to PTC in patients with previous Roux-en-Y surgery given potential advantages with this approach particularly if repeated procedures may be required.

\section{Note}

Informed written consent was obtained from the patient included in this case report.

\section{Funding}

None.

\section{Conflict of Interest}

None declared.

\section{References}

1 McPherson SJ, Gibson RN, Collier NA, Speer TG, Sherson ND. Percutaneous transjejunal biliary intervention: 10-year experience with access via Roux-en-Y loops. Radiology 1998;206(3):665-672

2 Fontein DBY, Gibson RN, Collier NA, et al. Two decades of percutaneous transjejunal biliary intervention for benign biliary disease: a review of the intervention nature and complications. Insights Imaging 2011;2(5):557-565

3 Amitha Vikrama KS, Keshava SN, Surendrababu NRS, et al. Jejunal access loop cholangiogram and intervention using image guided access. J Med Imaging Radiat Oncol 2010;54(1):5-8

4 Sandhu J, Swersky A, Salsamendi J, et al. Utilization of a modified Roux-en-Y anastomosis as an access point for percutaneous transjejunal cholangioplasty of recurrent biliary strictures. Cardiovasc Intervent Radiol 2019;42(12):1745-1750

5 Lopera JE, Hegg R, Bready E, et al. Complex biliary intervention: percutaneous small bowel access confirmation with cone-beam computed tomography and retrograde biliary obstruction recanalization. Gastrointestinal Intervention 2017;6(2):140-144 